\title{
RELIGIÃO, RELIGIOSIDADE, ESPIRITUALIDADE, ANCESTRALIDADE: TENSÕES E POTENCIALIDADES NO CAMPO DA SAÚDE
}

Religion, religiosity, spirituality, ancestrality: tensions and potentialities in the health field

\author{
Vivian Fukumasu da Cunha ${ }^{1}$ \\ Lucas Rossato ${ }^{2}$ \\ Fabio Scorsolini-Comin ${ }^{3}$
}

\section{RESUMO}

Os termos religião, religiosidade, espiritualidade e ancestralidade são tradicionalmente empregados com base em distinções terminológicas que consideram embates e sínteses epistemológicas em diferentes campos do saber, como a Psicologia, a Filosofia e a Psicologia da Religião, por exemplo. Pensando nos distanciamentos e nas aproximações entre esses termos, o objetivo deste estudo teórico é problematizar o modo como tais expressões têm sido empregadas nas produções científicas e nas práticas localizadas nas chamadas ciências da saúde. Observamos neste campo discursivo, por exemplo, um predomínio da expressão espiritualidade, de modo que tais produções a consideram mais apropriada por esta se apresentar mais apartada de referências religiosas e que poderiam, de algum modo, colocar em xeque a laicidade das práticas em saúde. Assim, oferecemos a possibilidade do uso combinado da expressão religiosidade/espiritualidade (R/E) como forma de cotejar as possíveis tensões existentes entre as mesmas e com vistas a fornecer indícios para uma assistência em saúde que efetivamente possa se valer desses domínios para a promoção de um cuidado integral e humanizado.

Palavras-chave: religião, religiosidade, espiritualidade, ancestralidade, assistência em saúde.

\begin{abstract}
The terms religion, religiosity, spirituality and ancestry are traditionally used based on terminological distinctions that consider clashes and epistemological syntheses in different fields of knowledge, such as Psychology, Philosophy and Psychology of Religion, for example. Thinking

\footnotetext{
${ }^{1}$ Psicóloga. Mestra em Psicologia pela Universidade Federal do Triângulo Mineiro. Doutoranda pelo Programa de Pós-graduação em Enfermagem Psiquiátrica da Escola de Enfermagem de Ribeirão Preto da Universidade de São Paulo. Doutorado sanduíche na Faculdade de Psicologia e de Ciências da Educação da Universidade do Porto, Portugal, com bolsa CAPES PrInt. Bolsista de Doutorado da CAPES. Membro do ORÍ - Laboratório de Pesquisa em Psicologia, Saúde e Sociedade.

2 Psicólogo. Mestre em Psicologia pela Universidade Federal do Triângulo Mineiro. Doutorando pelo Programa de Pós-graduação em Enfermagem Psiquiátrica da Escola de Enfermagem de Ribeirão Preto da Universidade de São Paulo. Bolsista de Doutorado da CAPES. Membro do ORÍ - Laboratório de Pesquisa em Psicologia, Saúde e Sociedade.

${ }^{3}$ Psicólogo e pedagogo. Mestre, Doutor e Livre Docente em Psicologia pela Universidade de São Paulo. Professor Associado do Departamento de Enfermagem Psiquiátrica e Ciências Humanas da Escola de Enfermagem de Ribeirão Preto da Universidade de São Paulo. Professor do Programa de Pós-graduação em Enfermagem Psiquiátrica e do Programa Interunidades de Doutoramento em Enfermagem da mesma instituição. Bolsista de Produtividade em Pesquisa do CNPq. Coordenador do ORÍ - Laboratório de Pesquisa em Psicologia, Saúde e Sociedade.
} 
about the distances and approximations between these terms, the objective of this theoretical study is to problematize how such expressions have been used in scientific productions and practices located in the so-called health sciences. We observe in this discursive field a predominance of the expression spirituality so that such productions consider it more appropriate because it is more removed from religious references and that could, in some way, put in check the secularity of health practices. Thus, we offer the possibility of the combined use of the expression religiosity/spirituality (R/S) as a way to compare the possible tensions between them and to provide evidence for health care that can effectively use these domains for the promotion of comprehensive and humanized care.

Keywords: religion, religiosity, spirituality, ancestry, health care.

\section{Introdução}

Um movimento de maior interesse e investigação no campo das relações entre espiritualidade, religião e saúde vem se acentuando nos últimos anos, destacando o Brasil como um dos países que mais estudam e publicam sobre essa temática, especialmente nas áreas de saúde mental, saúde pública e enfermagem (DAMIANO et al., 2016). Entre as razões para essa expansão encontramos no contexto brasileiro um cenário mais poroso para tais discussões, ainda que isso não signifique a assimilação desses vértices de modo natural e isento de embates de diferentes ordens.

Esse crescente interesse traz também uma problematização central que é a necessidade de um debate mais aprofundado acerca dos termos religião, religiosidade e espiritualidade que são utilizados pelas pesquisas nacionais e internacionais, bem como tais expressões também podem ser vistas nas práticas em saúde. Pensando nos distanciamentos e nas aproximações entre esses termos e a suas significações em campos diversos como a Psicologia, a Filosofia, a História e a Psicologia da Religião, por exemplo, propomos neste estudo teórico apresentar e problematizar o modo como tais expressões têm sido empregadas nas pesquisas em ciências da saúde e, por extensão, nas práticas profissionais desenvolvidas e corporificadas nesse campo. De que modo as práticas discursivas que empregam esses termos - com movimentos que podem priorizar determinadas expressões ou omitir outras, por exemplo - acabam produzindo formas de atuação na assistência em saúde, promovendo maior ou menor aproximação entre o cuidado e os elementos religiososespirituais? Trata-se, pois, de um estudo teórico elaborado a partir de uma revisão narrativa de literatura científica, cotejando tanto a produção nacional quanto internacional sobre o tema, 
oferecendo suporte para o endereçamento de reflexões situadas no campo de aplicação das ciências da saúde, nosso vértice de pertencimento para a abordagem dessas tensões.

\section{Breve contexto}

Para melhor compreender como chegamos nas discussões atuais é preciso recuperar, brevemente, o papel do movimento científico e também das religiões. Nomes consagrados como Aristóteles, Platão, Descartes e Pascal são conhecidos pelas suas contribuições sobre a compreensão do mundo, do conhecimento. As distinções entre razão e sentimento, racionalismo e empirismo fazem parte do movimento histórico da ciência, chegando ao embate entre duas epistemologias de compreensão para questões relevantes em Psicologia e espiritualidade, que são elas: a atual visão hegemônica de uma ciência intitulada por Karl Popper como Objective Knowledge, traduzida mundialmente e constantemente reeditada em português, e a perspectiva semeada por Michael Polanyi chamada Personal Knowledge, nunca traduzida para o português, que tem no cerne a pessoa no centro das atenções (MACHADO, 2016).

De acordo com Machado (2016), três mundos de objetos e naturezas distintas são reconhecidos por Karl Popper: o mundo 1, dos objetos efetivamente existentes, independentemente da percepção humana; o mundo 2, que é o lugar das nossas percepções diretas, dos referentes construídos por meios dos sentidos; o mundo 3, que é o mundo das teorias elaboradas sobre 0 mundo 2 e que devem ser confrontadas com ele. Em contrapartida, para o autor, a perspectiva de Michael Polanyi é outra e se mantem periférica, prevalecendo a ideia de objetivação do conhecimento na dinâmica de sua produção e circulação. Conforme Machado (2016), para Polanyi o conhecimento pessoal é composto de uma pequena parte explicitável por meio de definições precisas ou teorias, que convive com grande parte igualmente relevante que construímos do mundo tácito, incorporando elementos da cultura em que vivemos.

Essas noções de como encarar a construção do conhecimento se unem à importância das questões metodológicas nas escolhas para as investigações. Destaca-se que os conhecimentos do campo da saúde ou das ciências sociais levantam questionamentos sobre a complexidade dos fenômenos (ou objetos) investigados e da influência exercida, o que pode revelar escolhas distintas das que se tem por parte das tradições metodológicas (ALETTI, 2012). Dessa maneira, para 
aprender o conhecimento que se deseja, as estratégias de investigação desse conhecimento devem ser criticamente refletidas e coerentes ao seu objeto ou fenômeno.

Muito mais antigo que o movimento científico como conhecemos atualmente, a religiosidade e a espiritualidade estão presentes na experiência humana e vêm sendo retratadas, ao longo da história, por meio de sujeitos e objetos da cultura, arte, poesia, música, devoção, conflito, contemplação, aspiração e tantas outras atividades humanas (ZINNBAUER; PARGAMENT, 2005). Existem raízes históricas que ligam a religiosidade e a saúde, que são observadas ao longo dos séculos, em que a magia, a religião e a cura quase sempre andaram juntas (PINTO; FALCÃO, 2014). No início da Psicologia enquanto ciência, ao final do século XIX, grandes nomes também se preocupavam em estudar a religião, sendo que a disciplina da Psicologia da Religião existe desde 1890 (CARRETTE, 2012). Neste cenário é importante mencionarmos as contribuições de William James (JAMES, 2017).

De acordo com Říčan (2004), o termo espiritualidade surge nos estudos da religião como um “convidado indesejado”, causando confusão onde simplesmente William James usava o termo "religião". Famoso por ser um proeminente pesquisador que se interessava pela experiência religiosa, James e outros pesquisadores da época do final do século XIX fizeram um movimento de demarcar o interesse científico psicológico da experiência religiosa de outros conhecimentos como os filosóficos ou teológicos, por exemplo (CARRETTE, 2012). Acredita-se que com a popularização e soberania de alguns autores da Psicologia, bem como a ascensão de diferentes abordagens psicoterápicas, como a psicanálise e a análise do comportamento, que concediam pouco espaço para a experiência religiosa, esse interesse foi se distanciando até ficar novamente evidente na década de 1960, quando o termo espiritualidade começa a resgatar esse olhar (PARGAMENT, 2007).

O aumento no número de estudos sobre espiritualidade, religião e saúde acaba despontando, conjuntamente, com uma alteração na compreensão de saúde apresentada pela Organização Mundial da Saúde (OMS), em 1998. Considerando a integralidade do ser, a saúde passa a ser descrita como "um estado dinâmico de completo bem-estar físico, mental, espiritual e social e não somente a ausência de alguma doença ou enfermidade” (WORLD HEALTH ORGANIZATION, 1998, p. 4, grifo nosso). Ainda que a definição da OMS seja um movimento eminentemente político, há que se considerar que a inclusão da espiritualidade como vértice do cuidar promoveu 
e tem promovido diferentes repercussões, desde as consideradas mais cosméticas, que apenas destacam a existência do elemento espiritual, até mesmo de interpretações que buscam corporificar propriamente essa dimensão em pesquisas, em práticas, no ensino e na formação de profissionais de saúde. De fato, ancorando-nos na história brevemente trazida anteriormente, não podemos afirmar que foi a inclusão desse vértice que promoveu um incremento das reflexões na área, mas não podemos nos esquivar do inequívoco papel da OMS nas ações em torno da consideração da espiritualidade desde então.

Nesse conjunto que compõe a dimensão espiritual do ser, passa-se a estudar e destacar a relação da espiritualidade, da religiosidade e da religião com a saúde. Utilizamos o verbo “passase” porque ainda é pequeno o movimento de integração da dimensão espiritual no cuidado em saúde, com a operação de um movimento de exclusão e marginalização dos tópicos no ensino e educação em saúde, e com poucas instituições nacionais abordando o tema em seus currículos (HOLANDA; PEREIRA, 2020). De acordo com Holanda e Pereira (2020), existe uma dissonância entre a importância sobre o conhecimento e intervenção clínica do tema e a efetiva inserção na formação e prática profissional. Esse movimento pode ser observado tanto na graduação como na pós-graduação (CUNHA; SCORSOLINI-COMIN, 2019; CUNHA; ROSSATO; GAIA; SCORSOLINI-COMIN, 2020). No entanto, a condição espiritual em saúde já vem sendo considerada, debatida e proposta pelos pesquisadores de diversas maneiras, inclusive na problematização de qual seria o fenômeno que compõe a dimensão espiritual em questão: religião, religiosidade ou espiritualidade? A seguir, esses termos serão melhor apresentados.

\section{O debate dos termos religião, religiosidade e espiritualidade}

Religião, religiosidade e espiritualidade são fenômenos distintos e, muitas vezes, difíceis de se diferenciar (LUCCHETTI et al., 2015). Por essa razão é que a definição desses termos não encontra um consenso entre os pesquisadores. Além disso, Paloutizan (2017) chama atenção para a necessidade de se destacar o campo e autores por trás dos conceitos utilizados, pois essa variação

pode acarretar em aproximações ou distanciamentos. Reunimos aqui referências que são mais utilizados no campo da Psicologia e da ciência médica, já que o enfoque deste presente estudo é a interface com o campo da saúde. 
De acordo com Oman (2013), o termo religião parece ser o mais antigo e sua compreensão vem se mantendo mais estável no decorrer dos anos. De acordo com Pargament (2007), a religião é um construto amplo que inclui expressões pessoais e sociais, elementos objetivos e subjetivos e potencial para o bem e mal. Para Hill e Pargament (2003), nos tempos atuais, a religião vem sendo reificada em um sistema de crenças ou compromissos ideológicos. Para Oman (2013), a religião comporta componentes organizados e institucionais de tradições de fé.

Para Koenig et al. (2012), a religião envolve crenças, práticas e rituais relacionados ao sagrado. Segundo os autores, a religião também envolve crenças sobre espíritos (que podem ser considerados “bons” ou "ruins”, ainda que essa cisão possa ser questionada por algumas matrizes religiosas) e pode ser organizada e praticada em comunidade ou individualmente. Para o Conselho Regional de Psicologia de São Paulo (CRP-SP, 2015), que tem realizado importantes discussões no sentido de defesa de uma abordagem da religião com respeito à laicidade das práticas psicológicas, a religião é uma instituição social composta por um sistema de crenças e práticas reunidas que sustentam uma suposta relação com uma dimensão transcendental.

De acordo com Lazenby (2010), existiria uma diferença entre os termos “religião” e "Religiões”, sendo a primeira relacionada à experiência das pessoas em relação ao divino e a segunda, com letra maiúscula e plural, uma categorização das variadas tradições religiosas e seus conjuntos de objetos, como o Budismo e Cristianismo, por exemplo. No caso desse autor em tela, a religião compõe um conjunto de reações da pessoa diante da vida, o que parece caminhar para uma noção mais próxima do que vem sendo compreendida por outro termo, a religiosidade.

O termo religiosidade nem sempre é apresentado ou debatido pelos pesquisadores, sendo as distinções mais frequentemente realizadas entre as noções de religião e de espiritualidade (HILL; PARGAMENT, 2003; KOENIG et al. 2012; OMAN, 2013). De acordo com Précoma et al. (2019), a religiosidade refere-se a quanto um indivíduo acredita, segue ou prática uma religião, podendo ser organizada de maneira institucional (participação na igreja ou em dadas cerimônias e rituais, por exemplo) ou não, como em atividades como rezar, ler livros ou assistir programas religiosos por iniciativa própria. Para Mishra et al. (2017), a religiosidade guia e informa sobre as crenças espirituais do sujeito. Uma primeira interpretação possível acerca da religiosidade seria, portanto, a multiplicidade de formas de acessar, de expressar e de corporificar essa dimensão, não havendo uma só maneira ou então uma forma eminentemente institucional e exclusiva de fazê-lo. 
A análise conceitual de Bjarnason (2007) revela um consenso entre os traços que caracterizam a religiosidade, que abrange três focos: a) o reconhecimento de uma afiliação religiosa; b) a realização de atividades religiosas, como rezar ou frequentar cultos; c) a presença de crenças religiosas como, por exemplo, acreditar em um poder superior, nas escrituras - isso quando analisamos religiões que não se sustentam nas tradições orais, como nas religiões de matrizes africanas, por exemplo. A definição apresentada pelo CRP-SP (2015) é de que a religiosidade é um modo pessoal de lidar com ou vivenciar um sistema de crenças e práticas religiosas, que podem estar ou não ligadas a uma instituição. Conforme apresentado por Zinnbauer e Pargament (2005), a religiosidade captura o olhar para uma abordagem funcional, examinando o propósito de questões existenciais fundamentais. Ou, como descreve Paloutzian (2017), a religiosidade é um importante comportamento humano.

O que se observa nesse aparato conceitual é que religiosidade está intimamente conectada com a religião, mesmo que, conceitualmente, compreendam sentidos e/ou objetos diferentes. Aqui um segundo sentido sobre religiosidade pode ser endereçado: o de que a religiosidade pode se manifestar de diferentes maneiras, incluindo de modo mais intenso ou mais distanciado a adoção e participação em ritos institucionais - assim, abre-se a possibilidade de vivências de religiosidade mais institucionalizadas e coletivas, até mesmo expressões mais individuais e sem ancoragens institucionais.

Por fim, temos a apresentação do termo espiritualidade, que surge para o debate da problematização que se tem observado no campo da saúde. De acordo com Koenig (2012), a espiritualidade é distinta do humanismo, de valores, da moral ou da saúde mental pela sua relação com o que é sagrado e transcendente. Está intimamente conectada com o supernatural, com o místico e com a religião organizada, mas pode se estender a essa organização ou começar antes dela. Précoma et al. (2019) atestam que a espiritualidade é historicamente considerada um processo que se desdobrava dentro de um contexto religioso, mas recentemente tem sido separada da religião como uma construção distinta.

De acordo com o CRP-SP (2015), a espiritualidade é a busca de sentido para a vida que pode ou não estar ligada a uma crença religiosa. Para Paloutzian (2017), espiritualidade se refere uma amplitude de crenças ou práticas que podem ou não incluir crenças sobre estados ou entidades 
sobrenaturais. Com o seu distanciamento da teologia e, apesar de ser bastante popular, o termo

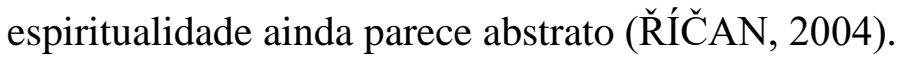

Outro termo que vem ganhando destaque mais recentemente é o de ancestralidade, embora o seu uso em publicações no campo das ciências da saúde seja praticamente inexistente dentro dos sentidos aqui compartilhados. Mas o uso contemporâneo da ancestralidade não se trata de uma inovação ou de uma criação dos pesquisadores, mas uma recuperação, ou seja, de um resgate ou, em outras palavras, de um processo de retomada de contato com uma dimensão que nos compõe como povos, culturas e sociedades. A ancestralidade seria um termo possível sobretudo considerando algumas matrizes religiosas que se opõem à consideração terminológica do termo religare, relacionado à religião. O candomblé, por exemplo, identificar-se-ia mais com a definição de ancestralidade por justamente considerar que os aspectos ditos “religiosos” não apenas fariam parte de um código compartilhado, mas, sobretudo, a partir de uma herança histórica. Essa herança também é ameaçada de ser apagada pelo racismo, pela intolerância religiosa e pela própria organização de um mundo no qual essa recuperação histórica e identitária nem sempre é valorizada, mas também temida, de modo. A ancestralidade, desse modo, envolveria a compreensão de quem se é enquanto povo, elemento central quando pensamos o candomblé na diáspora africana e todos os processos que se deram no sentido de apagamento dessa dimensão na contemporaneidade (GAIA; SCORSOLINI-COMIN, 2020).

Por essa interpretação, a ancestralidade ganharia espaço até mesmo em substituição aos termos religião, religiosidade e espiritualidade por rememorar e permitir a compreensão de que a existência individual não é apenas também uma existência coletiva, mas uma existência histórica, ancestral e que atravessa elementos macrossociais mais amplos, considerando marcadores de como as matrizes religiosas foram sendo compostas ao longo do tempo e as suas representações. O candomblé, como exemplo, é compreendido - para além de uma religião -, como um modo de vida, um modo de existir e também de resistir. A ancestralidade, nesse sentido, permitiria essa interpretação e essa possibilidade de endereçamento discursivo.

No entanto, retomemos, esse é ainda um termo que não tem sido encontrado na literatura em saúde, sendo que as discussões sobre religião, religiosidade e espiritualidade parecem ser conduzidas de modo apartado da dimensão da ancestralidade. Isso pode ocorrer, sobretudo, pelo fato de a literatura em saúde explorar mais a dimensão do sujeito na experiência com o 
transcendental, uma experiência sempre particular e que considera traços individuais, a personalidade e outros atributos bastante próximos de uma linguagem biomédica e positivista (CUNHA; SCORSOLINI-COMIN, 2021). Assim, haveria modos particulares de ler, de interpretar e de utilizar as dimensões religiosas e espirituais na saúde, ao passo que a ancestralidade traria à baila aspectos não apenas coletivos, mas também históricos. Entre os marcadores dessa ancestralidade também emergem processos com os quais a sociedade contemporânea possui bastante dificuldade de entrar em contato ou de reconhecer, como o racismo, a escravidão e o nosso passado escravocrata ainda recente, a intolerância religiosa e o preconceito de várias ordens, apenas para citar alguns exemplos. Por essa razão, a ancestralidade nas ciências da saúde ainda é um campo por ser construído ou, em outras palavras, a ser recuperado, resgatado.

Quando observamos a literatura no campo da saúde, sobretudo a que valida a incorporação das dimensões religiosas e espirituais para pensarmos tratamentos e desfechos de itinerários terapêuticos, a espiritualidade tem sido o termo eleito como o mais adequado - ou o mais validado/autorizado pelos pesquisadores. Se observarmos fortuitamente os seminários e congressos nesse campo, produzidos pelas ciências da saúde, notaremos que é a espiritualidade o termo central, considerado mais amplo, mais aceito e que desperta menos embates. Mas essa adoção não ocorre de modo neutro ou como um consenso dentro das especificidades terminológicos que temos discutido neste estudo. É importante destacar que a teia de complicação dessas questões conceituais está amarrada a uma noção que separaria a espiritualidade da religião (e religiosidade), isolando uma relação entre esses fenômenos. Sendo assim, apresentamos, a seguir, o embate entre os termos.

\section{O embate dos termos: religião (e religiosidade) versus espiritualidade}

Uma das grandes influências para o destaque das pesquisas que vêm sendo realizadas entre religião (e religiosidade), espiritualidade e saúde, é a popularização do termo espiritualidade. Um primeiro movimento que contribuiu para isso foi a Psicologia Humanista, nas décadas de 1950 e 1960, em que autores como Abraham Maslow, Viktor Frankl, Fritz Perls, entre outros, opuseramse às outras grandes correntes psicológicas, principalmente a psicanalítica e a comportamental, cujos principais autores negaram e rejeitaram o valor de aspectos religiosos e espirituais (PARGAMENT, 2007). Mesmo considerando a psicanálise, há que se destacar que o papel da religião nesse campo sempre foi de menor destaque e até mesmo de recusa a esse debate. Carl Jung 
foi um dos psicanalistas que mais investigou o campo religioso, mas também foi atacado justamente por esse interesse, contrapondo-se a outros seguidores contemporâneos de Freud, como Jacques Lacan, Melanie Klein e D. W. Winnicott.

Em contraposição ao movimento de apagamento da dimensão religiosa-espiritual nas duas correntes predominantes à época - psicanálise e comportamentalismo - muitos dos autores que compõem a corrente humanista trataram de debater e compreender o papel da religião (e religiosidade) e da espiritualidade como um recurso e potencialidade humana em seus trabalhos. Um dos exemplos é Viktor Frankl, que a explorou a partir das noções de busca pelo sentido e pelo significado para vida, da morte e morrer, do alívio e do sofrimento (ARRIEIRA et al., 2017).

Conjuntamente a esse movimento na Psicologia, nas décadas de 1970 e 1980 acontecia um movimento social denominado de New Age (Nova Era). De acordo com Maraldi (2016), a mentalidade new age passa a incorporar aspectos que foram crescendo com o pluralismo e a globalização, em que a identidade religiosa ganha uma forma mais fluida, nômade, ligada a tudo e nada em específico. Para o autor, o sagrado passa a ser vivido individualmente, perdendo um pouco a sua força coletiva, em que a religião deixa de ser a única fonte detentora do discurso sobre o sagrado. Nessa época também passam a ser frequentes as atitudes sociais e culturais que se contrapunham a muitos dos dogmas defendidos por algumas religiões, sobretudo as de base cristã. Tabus como o sexo antes do casamento, de expressão da sexualidade e de comportamentos considerados transgressores passam a não encontrar um lugar no universo religioso conservador, de modo que a religiosidade e a espiritualidade passam também, de algum modo, a serem combatidas ou então a serem consideradas como dimensões menos importantes do que em outros momentos históricos.

Alguns pesquisadores discutem esse posicionamento de que a religiosidade e a espiritualidade se remetem ao sagrado, sem a proposição religiosa, pois essa seria uma visão muito inespecífica, em que há a possibilidade do sagrado ser qualquer coisa (uma lata de cerveja, um time de futebol, uma árvore), perdendo o sentido dos estudos e colocando em evidência que não há uma essência ou singularidade que constituiria esse "sagrado" (PALOUTZIAN, 2017). Influenciados por esses movimentos, abarcando a possibilidade de um sagrado alheio à religião (e religiosidade) é que surgiu uma nova forma de identidade denominada pelos pesquisadores como "espiritual, mas não religioso” (PARGAMENT, 2007). 
Essa nova identificação de pessoas que aceitam o espiritual, mas não o religioso, atribuindo ao religioso um valor negativo, é muito forte no campo das ciências da saúde. Essa popularização da espiritualidade ganhou notoriedade e interesse das pessoas e pesquisadores, mas fez emergir uma tensão conceitual que antes era indistinta (ZINNBAUER; PARGAMENT, 2005). A religião, então, passa a ser caracterizada por formas tradicionais, rituais, instituições e ensinamentos ortodoxos, rigidez, falta de sentimentos, atitude reacionária, moralização, enquanto que a espiritualidade passa a significar algo novo, interessante, espontâneo, criativo e universal (̌̌ÍČAN, 2004).

Religião (e religiosidade) e espiritualidade passam a ter uma conotação de oposição. De acordo com Zinnbauer e Pargament (2005), religião (e religiosidade) passam a ser compreendidas como um substantivo, sendo estáticas e perdendo o caráter dinâmico, com características institucionalizadas, impositivas, baseadas nas crenças e, consequentemente, com uma acepção negativa diante da alternativa que é a espiritualidade. Por sua vez, a espiritualidade passa ser funcional, dinâmica, com a possibilidade de despertar a autonomia do ser, que levaria à transcendência, ao sentido de vida, completude, potencial inato, baseado na experiência e conexão com o que vem do coração e, consequentemente, sendo considerada benéfica e positiva para os indivíduos. Com isso, o que se assiste é uma mudança de paradigma.

De acordo com Koenig et al. (2012), a religião (e religiosidade) passam a ser compreendidas como um componente que pode ou não fazer parte da espiritualidade. Outra possibilidade diante da perspectiva complexa do que seria espiritualidade é que esta comporia aspectos que podem envolver a religião, mas também outros componentes como, por exemplo, sentido, propósito, esperança. De acordo com os autores, esses seriam os modelos de compreensão para os estudos científicos e seriam diferentes de uma quarta possibilidade, que é o modelo de investigação clínica. No modelo de investigação clínica, considera-se a espiritualidade mais abrangente, incluindo possibilidades de religião (e religiosidade), componentes como, por exemplo, sentido, propósito, esperança e também a compreensão do secular.

Um ponto a destacar é que realçar a espiritualidade como sendo uma dimensão "boa” e religião (e religiosidade) como “ruim” pode levar à ignorância de se deixar de lado a investigação do potencial negativo e destrutivo de uma vida espiritual (ZINNBAUER; PARGAMENT, 2005). Tanto a religião (e religiosidade) como a espiritualidade podem apresentar um impacto positivo ou 
negativo na saúde física e mental (KOENIG, 2012). No entanto, a problematização dessas diferenciações e olhares para esses fenômenos da religião, religiosidade e espiritualidade também são discutidas a partir de suas semelhanças, como abordado a seguir.

Antes disso, é preciso apenas considerar que as ciências da saúde podem se beneficiar desse movimento no sentido de que a espiritualidade passa a ser um conceito mais palatável, inclusive para os pesquisadores e profissionais que defendem a ideia de uma atuação que não considerem essa dimensão. Mesmo quando se critica a proximidade com essa dimensão, a menção à espiritualidade parece gozar de uma maior penetração no universo médico, por exemplo, historicamente construído e solidificado a partir do modelo biomédico e da ciência positivista. O movimento que se opera é o de que a espiritualidade, na acepção abordada nesta seção, acaba sendo uma alternativa ao encontro com a religião e a religiosidade, um movimento de ruptura com a possibilidade de que o religioso - e seus símbolos e códigos - habitem também o campo de atuação biomédico, alinhado a paradigmas rígidos do que é o conhecimento científico e do que é uma prática baseada nesses princípios. Aqui o religioso é contraposto ao que pode ser um cuidado baseado em paradigmas de uma ciência objetiva - ou, como recentemente tem sido evocado, baseado em evidências.

No paradigma científico, desse modo, não há espaço para a religião e para o religioso, muito menos para o ancestral, muitas vezes associado exclusivamente a religiões mais tradicionais como o candomblé e seus marcadores sociais e culturais que nos colocam diante das vivências de preconceito, racismo e intolerância em relação às matrizes africanas. Mas abre-se uma brecha: a espiritualidade. Nessa condição, também a espiritualidade passa a ser composta como uma dimensão esvaziada, em um movimento de cisão com a composição histórica desse conceito ou, em outras palavras, sem reverência à sua ancestralidade, como explicitado anteriormente. Pelo modo como os termos religião, religiosidade e espiritualidade emergem de modo mais frequente na literatura nas ciências da saúde, a seção seguinte explorará de modo mais detido essas noções.

\section{Desafios para definir religião, religiosidade e espiritualidade}

Pesquisadores sobre o tema atestam que a complexidade de se definir o que é religião, religiosidade e espiritualidade reside no fato de serem fenômenos muito próximos (HILL et al., 2000; ZINNBAUER; PARGAMENT, 2005; OMAN, 2013). A crítica em relação à distinção entre 
religião (e religiosidade) versus espiritualidade é problemática porque tanto um quanto o outro apresentam características comuns (HILL et al., 2000). Apesar dos termos apresentarem semelhanças entre si e possuírem uma sobreposição inevitável pelo fato de se referirem a experiências, sentimentos e inclinações muito próximas, consistem em dimensões com significados e características amplas e diferentes.

Hill e colaboradores (2000), assim como Zinnbauer e Pargament (2005), apontam que religião (religiosidade) e espiritualidade estão presentes na cultura e não são reduzíveis a outros processos ou fenômenos, desenvolvendo-se no curso da vida. São inerentes às condições sociais e psicológicas, são constructos complexos e multidimensionais, estão relacionados a afetos, emoções, cognição, moral, traços de personalidade ou de autoidentificação. Além disso, a distinção entre os termos parece ser uma preocupação mais acadêmica e científica e, consequentemente, da figura de autoridade por trás do discurso científico do que da população em geral, pois a maioria das pessoas se define como religiosa e espiritual (ZINNBAUER; PARGAMENT, 2005) ou podem não fazem uma distinção entre conceitos, o que pode ser mais ou menos predominante a depender da cultura de cada país (CUNHA; PILLON; ZAFAR; WAGSTAFF; SCORSOLINI-COMIN, 2020). Assim, a necessidade de definir - aproximando ou distanciando esses termos - parece caber mais aos pesquisadores, de modo que tais atravessamentos acabam sendo de pouco interesse, por exemplo, para pacientes-clientes-usuários na linha de cuidado. O que se espera, muitas vezes, é uma atitude de acolhimento e de possibilidade de experiência dessa dimensão ampla no momento do tratamento, não sendo relevante a precisão terminológica adotada.

Levando em consideração os aspectos apresentados até aqui e compreendendo os tensionamentos epistemológicos existentes, propomos apresentar a terminologia combinada religião/espiritualidade ou religiosidade/espiritualidade (R/E) como uma possibilidade de emprego, sobretudo, no campo das ciências da saúde. Assim, é importante reforçar que essa possibilidade responde eminentemente à necessidade de tornar possível o emprego desses elementos como vértices do cuidado, assim como recomendado pela OMS, embora com poucos direcionamentos claros nesse sentido, o que também tem contribuído para a construção de diversas possibilidades desse emprego - dos considerados mais aprofundados até os mais cosméticos e com pouco valor para a prática em saúde e para o cuidado humanizado e integral. 


\section{Uma possibilidade integradora no campo das ciências da saúde: o uso do termo combinado} religiosidade/espiritualidade $(\mathrm{R} / \mathrm{E})$

A religiosidade e a espiritualidade têm sido cada vez mais debatidas no campo das ciências da saúde, sendo problematizadas as definições desses conceitos e as suas articulações com o cuidado (PUCHALSKI et al., 2014; NASH; NASH; DARBY, 2015; STEINHAUSER et al., 2017). Estudos realizados no contexto brasileiro e internacional têm evidenciado esforços em compreender as formas pelas quais essas dimensões perpassam as vivências dos sujeitos e interfere em seus comportamentos e nas suas subjetividades (ARRIEIRA et al., 2017; GALLARDOPERALTA, 2017; SWINTON et al., 2017).

As publicações científicas sobre religiosidade e espiritualidade têm apresentado dados significativos que permitem refletir e compreender como essas dimensões interferem na vida das pessoas. Ao descreverem esse fenômeno os estudos também têm contribuído com o debate acerca do que se constituem esses conceitos, havendo uma tendência no uso do termo combinado R/E para expor essas dimensões (CUNHA; PILLON; ZAFAR; WAGSTAFF; SCORSOLINI-COMIN, 2020; DAMIANO et al., 2016; KOENIG, 2012; MISHRA et al. 2017).

A literatura científica sobre religiosidade e espiritualidade tem se dedicado a essa reflexão com o objetivo de apresentar definições para esses dois termos. Tais discussões são apresentadas para delimitar esses conceitos, além de pontuar aproximações e distanciamentos. Ao longo dos anos os termos religiosidade e espiritualidade eram vistos como um único aspecto. Porém, com o advento do século XX vimos uma distinção gradual entre religião como práticas e crenças sobre o sagrado ou o divino e a espiritualidade, que passou a significar algo mais intimamente relacionado à experiência emocional (KING; KOENIG, 2009).

Como um construto, a R/E tem (geralmente) a ver com uma visão de mundo que inclui crenças em uma realidade transcendental que fornece significados e propósitos para a vida das pessoas, podendo também ocorrer em um contexto de tradições religiosas em uma comunidade, manifestando-se por meio da religião, ou uma crença mais centrada no indivíduo em atividades individuais, expressando-se na espiritualidade, ou ambos os casos (BRAAM; KOENIG, 2019). A R/E possui uma sobreposição inevitável pelo fato de se referir a experiências que se aproximam em determinados aspectos, sendo dimensões ligadas a contextos que se assemelham, referem-se a comportamentos, são direcionadas a um mesmo objetivo que é a busca pelo sagrado, o 
transcendental, a fenômenos de natureza mística e existencial. Assim, as publicações têm utilizado da nomenclatura combinada ao descrevê-las, mas, ao mesmo tempo, explicam suas compreensões para cada um dos termos, uma vez que se trata de um terreno delicado, permeado por discussões complexas, algumas delas referidas no presente estudo.

Um importante estudo realizado por Koenig (2012), por exemplo, com o objetivo de evidenciar o perfil de produções científicas sobre religiosidade, espiritualidade e saúde apresentou a problemática dos termos religiosidade/espiritualidade/religião em sua descrição. No trabalho mencionado, Koenig faz uma explanação dos conceitos justificando ao mesmo tempo que são termos amplos, com semelhanças e dicotomias e, na sequência, menciona que usará o termo combinado. Neste estudo, assim como ocorre em outros (CUNHA; ROSSATO; GAIA; SCORSOLINI-COMIN, 2020; CUNHA; PILLON; ZAFAR; WAGSTAFF; SCORSOLINICOMIN, 2020), o autor apresenta uma justificativa para o uso da nomenclatura combinada, sendo este um procedimento usual em parte das publicações.

O mesmo acontece com conceitos derivados da temática como, por exemplo, o coping religioso/espiritual (CRE), conceito este criado por Pargament (1997). O CRE faz uso de crenças e comportamentos com base na fé, podendo incluir aspectos da religião, espiritualidade e ou crenças pessoais como um recurso para lidar com as adversidades e estresse (PANZINI; BANDEIRA, 2007). Isso quer dizer que também não se limita a apenas um dos aspectos (religiosidade ou espiritualidade), mas utiliza-os na ideia de complementariedade, tendo como foco principal os seus empregos no enfrentamento de uma situação complexa, como nos casos de adoecimento (CORRÊA; BATISTA; HOLANDA, 2016; ROSSATO; ULLÁN; SCORSOLINICOMIN, 2021). Assim, pode-se dizer que os elementos religiosos e espirituais parecem ocupar um espaço menor quando discutimos o coping, de modo que o termo CRE tem como objetivo a reflexão prática sobre como o ser humano constrói formas de enfrentar determinadas situações apoiando-se nesses elementos e não necessariamente propondo o adensamento desses/nesses vértices.

Apesar de no meio acadêmico ser importante a divisão dos termos para a descrição e a compreensão do fenômeno, o uso da terminologia combinada R/E seria relevante diante de um cenário em que são múltiplas as definições que poderiam ser apresentadas para expressarem esses conceitos e ainda assim incorrendo ao risco de deixar de lado aspectos significativos sobre as 
mesmas. Considerando que a R/E é atrelada aos aspectos culturais e sociais das pessoas, percebese uma multiplicidade de práticas, crenças, modos de compreender esses fenômenos em níveis individual e coletivo.

A leitura crítica que se faz das publicações que apresentam o termo combinado (R/E) é de que as investigações não estão preocupadas em definir propriedades específicas desses fenômenos, nem se ater a aspectos epistemológicos que orientam o emprego dessas noções, mas os efeitos que eles apresentam, que são mediados pela subjetividade. Levando em consideração de que é a subjetividade que nomeia a vivência, podemos considerar uma apropriação e efeito que pode ser "positivo" ou "negativo”, conforme o que temos encontrados nas pesquisas em saúde (KOENIG, 2012; MISHRA et al. 2017). Essa noção de uma R/E que pode ser positiva e/ou negativa, apesar de simplista, é o que vem fazendo com que os estudos sobre a temática em saúde fiquem mais evidentes e atrativos.

Aqui cabe uma justificativa maior para esse emprego. Em que pese a necessidade de incluir a dimensão da R/E nas pesquisas e nos cenários de cuidado, os embates epistemológicos poderiam dificultar, de fato, que esses vértices pudessem compor a assistência em saúde. Essa discussão, nessa interpretação, acabaria se distanciando da prática, sendo cotejada apenas em termos teóricos.

Embora essas reflexões sejam muito importantes para que possamos empregar nomenclaturas que efetivamente descrevam nossas intervenções e as epistemologias que orientam as nossas práticas de pesquisa, o termo combinado parece ser suficientemente amplo e generalista para uma tripla função: primeiramente para permitir, de fato, uma reflexão prática dessa dimensão no fazer em saúde - contemplando, por exemplo, as diretrizes da OMS; em segundo lugar, para permitir a inclusão de uma multiplicidade de experiências - pessoais, coletivas, ancestrais - que podem fazer parte do universo religioso/espiritual do sujeito, sem que essas experiências tenham que ser categorizadas como sendo mais da ordem do religioso, do espiritual ou do ancestral; e, por último, por trazer à baila o que orienta a maioria das práticas em saúde, que é a relação de tal adoção com os desfechos em saúde - em outras palavras, de como a R/E pode ser útil para a assistência em saúde. Em termos desse terceiro aspecto, especificamente, a comprovação de que a R/E poderia favorecer tratamentos e itinerários terapêuticos poderia constituir uma evidência ou um indício para que, de fato, essa dimensão pudesse ser efetivamente incorporada no cuidado. Essa 
evidência já é referida de modo importante na literatura científica (CUNHA; PILLON; ZAFAR; WAGSTAFF; SCORSOLINI-COMIN, 2020; PERES et al., 2018).

Diante dos atuais processos históricos-sociais, os pesquisadores da área da saúde passaram a ter uma maior receptividade e abertura para consideração de um sujeito integral, composto biopsico-socio-espiritualmente. Fica mais forte a crítica ao positivismo apregoado pela ciência e até mesmo a necessidade de os próprios profissionais da saúde terem sua R/E reconhecida como um componente que lhes constitui e compõe um olhar necessário para consigo e para com o outro (CUNHA; SCORSOLINI-COMIN, 2020; VASCONCELOS, 2015). Passamos a reconhecer, desse modo, o sujeito como protagonista da sua saúde e, com isso, abrimos espaço para o diálogo interprofissional e a presença de vários métodos de investigação científica. É nesse espaço de confluência dos vários campos que articulam o saber que se tem a problematização do olhar sobre as dificuldades de definir cada um dos termos.

Pensando no contexto da saúde, mas não negando as distinções epistemológicas de cada um dos termos - religião, religiosidade e espiritualidade -, a terminologia combinada R/E se mostra receptiva e acolhedora para considerar o processo sócio-histórico e subjetivo que compõe a dimensão espiritual. A preferência pelo uso do termo espiritualidade, especialmente apartado de questões religiosas, pode levantar implicações equivocadas e afastadas de uma realidade culturalmente construída, dado que noções religiosas compõem as culturas no mundo todo, em maior ou menor grau (CUNHA; PILLON; ZAFAR; WAGSTAFF; SCORSOLINI-COMIN, 2020). A preponderância ou opção pelo termo espiritualidade pode denunciar, ainda, como temos anunciado ao longo do presente estudo, o viés hegemônico e centralizador que alguns países ocupam como referência no cuidado, sobrepondo a ênfase de suas culturas.

De modo semelhante, como já justificado anteriormente, a exclusão do termo ancestralidade deve ser pontuada, sendo uma noção que se distancia desse paradigma hegemônico ao recuperar processos históricos que foram sendo intencionalmente apagados ao longo do tempo, o que se corporifica no modo como as religiões tradicionais e de matriz africana precisaram e ainda precisam resistir. As ciências da saúde, desse modo, parecem estar apartadas dessa discussão, sendo que um termo bastante tradicional - a ancestralidade - ainda emerge como uma novidade, uma inovação em nosso atual contexto. Recuperar esses elementos parece ser uma recomendação potente para os pesquisadores desse campo. 
Além disso, a exclusão do vértice religioso, privilegiando o termo espiritualidade, também pode revelar tensionamentos profissionais importantes que ganham destaque no modelo biomédico que ainda continua orientando a assistência em saúde. Nesse modelo e nesse modo de produzir saúde, há pouco ou nenhum espaço para a dimensão religiosa, considerada um elemento subjetivo, que é trazido pelo sujeito em processo de cuidado. Ainda que esse sujeito possa fazer uso de recursos baseados nesse vértice religioso, não é tarefa do profissional de saúde lidar com esse elemento. Dentro desse mesmo modelo biomédico e hospitalocêntrico, aventar que o profissional de saúde poderia também ser ouvido em sua dimensão religiosa seria algo incompatível com uma ciência tecida a partir de rígidos parâmetros e orientada pela doença, pelos aspectos fisiopatogênicos do adoecer.

Essa relação reforça, em outra medida, a ideia de que "religião e ciência não se misturam” e, portanto, a primeira não deve fazer parte do ensino e do cuidado em saúde. No entanto, destacase que a religião em si, como aspecto que compõe crenças e dogmas próprios, não será o questionamento da ciência, nem seria eticamente correto fazê-lo (BIZERRIL; NEUBERN, 2012). O interesse da ciência é pelos aspectos que compõem a relação, o que entendemos como R/E. Neste momento, não temos evidências que confirmam uma não relação da religiosidade e espiritualidade (HILL et al., 2000; ZINNBAUER; PARGAMENT, 2005; OMAN, 2013). Pelo contrário, de acordo com os modelos que são encontrados, a espiritualidade incluiria a possibilidade da religião (e religiosidade), mesmo que possa se estender além dela (KOENIG et al., 2012). O termo combinado, nesse sentido, parece sustentar essas tensões e essas especificidades.

No entanto, se considerarmos que as evidências ainda não são suficientes para excluir a religião (e religiosidade) da espiritualidade, a não ser por instrumentos ou medidas que deixem isso claro na investigação, devemos considerar que a relação entre religiosidade e espiritualidade é muito maior e mais predominante do que seu contrário. Isso porque dados confirmam que 92\% da população nacional possui uma religião (INSTITUTO BRASILEIRO DE GEOGRAFIA E ESTATÍSTICA, 2010). Em outros países, como Estados Unidos, 18\% dos entrevistados se identificaram não ter uma religião de preferência e para 53\% deles a religião é importante na vida (NEWPORT, 2016). Já na União Europeia, de acordo com o Eurobarometer (2005), 18\% da população declaram não acreditar em entidade espiritual, Deus ou força vital. Nessa média, os países que menos declaram acreditar em uma entidade espiritual, Deus ou força vital são a França 
(33\%) e a República Checa (30\%). Em contraposição, Polônia (98\%) e Malta (97\%) são os países que mais declaram acreditar em Deus ou força vital. Tomar como base o "espiritual, mas não religioso” ainda não é o predominantemente encontrado nas culturas, mas, possivelmente, é a tendência encontrada na população científica e dos profissionais da saúde se comparados com a população em geral (HILL et al., 2000; MOREIRA-ALMEIDA et al., 2006).

\section{Religiosidade/espiritualidade e saúde: evidências para a ampliação de um debate perene}

Historicamente a religiosidade, a espiritualidade e a ancestralidade têm sido evidenciadas como dimensões significativas na vida dos sujeitos quando considerada a tríade saúde-doençacuidado, principalmente em contextos sociais em que as mesmas são presentes e com grande relevância para os sujeitos. Desde 1998, com a inserção da dimensão espiritual no conceito de saúde da OMS, tem crescido de forma significativa o número de publicações sobre a influência da R/E na saúde física, mental e nos aspectos subjetivos das pessoas (LUCCHETTI; LUCCHETTI, 2014; ZIMMER et al., 2016; SHATTUCK; MUEHLENBEIN, 2020), o que demonstra que essas dimensões fazem parte do repertório de vida das pessoas na maioria das culturas e está sendo investigada em diferentes campos do conhecimento.

A saúde humana possui múltiplas fontes importantes para sua manutenção, tais como: materiais, sociais, culturais e espirituais. Todos os sujeitos em sua constituição básica caracterizamse como seres biopsicossociais e espirituais, necessitam de materiais, alimentos nutritivos, ar, água, abrigo adequado, precisam de famílias, amigos, comunidades, de cultura e da espiritualidade (ECKERSLEY, 2007), que dá sustentação e sentido para as vivências, além de proporcionar a conexão com o que é sagrado e transcendental.

As interlocuções entre religiosidade, religião, espiritualidade, ancestralidade e saúde são antigas e fazem parte do processo evolutivo da sociedade, sendo presentes desde os primórdios da história da humanidade. A história mais recente tem mostrado essas interrelações ao descrever, por exemplo, que os primeiros hospitais do ocidente para cuidar dos doentes da população em geral foram construídos por organizações religiosas e administrados por ordens religiosas (KOENIG, 2012). Na Idade Média e durante a Revolução Francesa, os médicos muitas vezes eram clérigos e por centenas de anos as instituições religiosas foram responsáveis por licenciar médicos para 
praticar a medicina (KOENIG, 2012). Na história da Enfermagem esses elementos também se mostram presentes, com a participação de religiosas na construção e consolidação desse fazer profissional e de determinados protocolos de cuidado empregados até hoje.

Ainda hoje, inúmeras instituições de saúde vinculadas a ordens religiosas e espirituais são responsáveis pela assistência e cuidado da saúde da população. Além disso, tem crescido o interesse pelo estudo dos aspectos religiosos e espirituais em uma variedade de disciplinas científicas e de saúde, incluindo, mas não se limitando, à Psicologia, Medicina, Enfermagem, Serviço Social, Aconselhamento, Sociologia, entre outras (CUNHA; SCORSOLINI-COMIN, 2019; MACDONALD et al., 2015).

Na literatura científica nacional e internacional é possível encontrar estudos que evidenciam as relações entre religiosidade, espiritualidade, religião, ancestralidade e saúde apresentando pesquisas que descrevem como essas dimensões perpassam as práticas de cuidado e as vivências de pessoas adoecidas (DHAR et al., 2013; ZIMMER et al., 2016; WEATHERS, 2018; WALTERS; BENJAMINS, 2021). A utilização da religiosidade e da espiritualidade pode ser considerada essencial nos contextos de saúde uma vez que construir mecanismos de resiliência e mecanismos de proteção para o enfrentamento de situações difíceis podem influenciar no bem-estar, na qualidade de vida e na forma como os sujeitos irão perceber o que vivem.

De acordo com Southard (2020), as pesquisas em neurociência e psicoimunologia fornecem evidências de que o sistema imunológico, o sistema nervoso central e a prática espiritual funcionam como um todo integrado e que pensamentos, percepções e sentimentos podem alterar a imunidade, construir resiliência e ajudar na recuperação de uma crise de saúde. Para o autor, treinamento de resiliência e os recursos espirituais relacionados às habilidades de enfrentamento, incluindo autocuidado, são componentes importantes de qualquer desafio de saúde.

As pesquisas científicas baseadas em evidências começaram a explorar os benefícios objetivos da R/E para a saúde. Os estudos vêm evidenciando dados significativos sobre as influências dessa na vida dos sujeitos, tais como: redução na morbidade e mortalidade, maior expectativa de vida, melhores índices de enfrentamento de situações difíceis, taxas mais elevadas de comportamentos positivos de saúde, taxas mais baixas de consumo de álcool, tabaco e outras drogas, entre outros aspectos (SHATTUCK; MUEHLENBEIN, 2020). Essas evidências demonstram como a R/E perpassa o contexto saúde-doença-cuidado e seus reflexos na qualidade 
de vida, no bem-estar, nos modos de enfrentamento, na forma como as pessoas podem se comportar diante de intercorrências que vivenciam em sua saúde, na resiliência, expondo os impactos na saúde física, na saúde mental e nos relacionamentos sociais (GALLARDO-PERALTA, 2017; PERES et al., 2018; SATARIANO, 2020; SZCZEŚNIAK; KROPLEWSKI; SZAŁACHOWSKI, 2020; SCHWALM et al., 2021).

As associações entre religiosidade/religião/espiritualidade e saúde têm permitido, dessa forma, encontrar estudos que avaliam os impactos positivos e negativos dessa dimensão. Os desdobramentos dessa articulação têm como resultado a produção de conhecimentos significativos que refletem a influência da R/E no ajustamento psicológico diante de situações complexas como o adoecimento (BOVERO et al., 2016; JIMENEZ-FONSECA et al., 2018), na manutenção da esperança (COSTA et al., 2019), a lidarem com o final da vida (SWINTON et al., 2017), auxiliando a lidar com a depressão (BRAAM; KOENIG, 2019), a ansiedade (BARRERA et al., 2012), a lidar com o transtorno de estresse pós-traumático (SMOTHERS; KOENIG, 2018), fornecendo suporte social (GALLARDO-PERALTA, 2017), na redução dos índices de suicídio, no desenvolvimento de transtornos por uso de substâncias, entre outros (KOENIG; AL-ZABEN; VANDERWEELE, 2020).

Portanto, os dados aqui sumarizados demonstram as significativas associações entre R/E e saúde descritas na literatura científica. Tais aspectos reforçam a relevância da discussão e reflexão dessas dimensões nas investigações científicas no campo da saúde, em especial de estudos que problematizem as lacunas existentes na produção do conhecimento nessa área.

\section{Considerações finais}

Este estudo objetivou apresentar discussões e reflexões sobre religião, religiosidade, espiritualidade, ancestralidade e saúde, resgatando aspectos teóricos referentes às definições desses conceitos, problematizado seu uso e suas articulações na produção do conhecimento científico e nas práticas no campo das ciências da saúde. Os dados apresentados fornecem um quadro dentro de um contexto vasto de publicações científicas nacionais e internacionais que tem se ocupado de debater os aspectos referentes a esses conceitos e as implicações para as práticas da assistência e cuidado em saúde representadas por diferentes categorias profissionais. 
Debater o uso dos referidos termos e suas interrelações com a saúde é uma tarefa delicada, inserida em um contexto permeado por polêmicas e discordâncias. Apesar dos inúmeros esforços empreendidos por pesquisadores renomados e com diferentes formações, ainda não existe um consenso e um padrão bem delimitado de como poderiam ser descritos os conceitos. Assim, a delimitação dos mesmos torna-se uma tarefa que requer atenção devido à multiplicidade de significados socialmente atribuídos aos mesmos, estando diretamente ligados à cultura das pessoas. Além disso, é imprescindível considerar que, em se tratando da R/E, pode ser encontrada uma diversidade de termos, formas de vivenciar e expressões dessas dimensões na vida cotidiana.

Uma alternativa encontrada para abarcar os múltiplos significados atribuídos aos aspectos religiosos e espirituais e destacada no presente estudo é a utilização do termo combinado R/E, uma vez que o interesse nesses casos não é a separação didática entre os termos, mas de expressar os sentidos vivenciais atribuídos a essas dimensões pelos sujeitos que são entrevistados nas pesquisas e que são atendidos nos contextos de saúde. No entanto, destacamos que o termo combinado é uma possibilidade para a que a R/E possa, de fato, ultrapassar as discussões teóricas e possa ser coloca em prática ou, ainda, refletida a partir da prática. A busca por uma síntese, sobretudo atendendo a necessidades práticas no campo da assistência em saúde, não deve invalidar todo um percurso epistemológico que orienta as tensões entre esses termos. O termo combinado, portanto, não se propõe a solucionar esses embates nem enfraquecê-los, mas justamente permitir a corporificação das religiões, das religiosidades, das espiritualidades e das ancestralidades na assistência em saúde.

As evidências das relações entre $\mathrm{R} / \mathrm{E}$ e o cuidado em saúde têm sido amplamente discutidas nas publicações científicas, demonstrando sua relevância nos processos de enfrentamento de situações de adoecimento, de lidar com situações de luto e outros problemas cotidianos vivenciados em equipamentos de saúde. Do mesmo modo, essa dimensão pode ser uma importante aliada, fornecendo suporte social, interferindo no bem-estar e na qualidade de vida. Pela literatura aqui recuperada, que emprega predominantemente as terminologias espiritualidade e religiosidade, destaca-se a necessidade de que as questões terminológicas não ocupem uma posição de inferioridade diante das evidências científicas que priorizam os desfechos nas ciências da saúde. Assim, uma maior abertura para as reflexões em torno do termo religião e da recuperação da ancestralidade podem ser propostas importantes para os estudos vindouros. A síntese aqui 
recuperada por meio do termo $\mathrm{R} / \mathrm{E}$ parece ser transitória em alguma medida, convocando pesquisadores e pesquisadoras para um trabalho perene.

É importante considerar que mesmo diante dos esforços em sintetizar os amplos debates sobre os termos religiosidade, religião, espiritualidade, ancestralidade e suas conexões com os aspectos de saúde, esse estudo apresenta limitações que devem ser consideradas. Parte das limitações reside no fato de que não é possível cotejar todos os atravessamentos históricos e epistemológicos existentes nesse campo. Logo, é necessária uma leitura ampla de diferentes materiais que permitam fazer uma síntese parcial das discussões referentes a esses aspectos. Ainda que pesem essas limitações ou circunscritores de qualquer estudo de caráter teórico, reforçamos que a presente reflexão apresenta não apenas os principais embates existentes e a sua evolução ao longo do tempo, mas, sobretudo, uma possibilidade integradora - por meio do termo combinado $\mathrm{R} / \mathrm{E}$ - como resposta para uma atuação em saúde mais humanizada e humanizadora, respeitando as religiões, as religiosidades, as espiritualidades e as ancestralidades que atravessam práticas e saberes tanto de profissionais de saúde quanto de pacientes-clientes-usuários e suas famílias. Que esse debate possa ser perenemente aquecido e revisitado por novas contribuições.

\section{REFERÊNCIAS}

ALETTI, M. A Psicologia diante da religião e da espiritualidade: questões de conteúdo e de método. In FREITAS, M. H.; PAIVA G. J. (Orgs.), Religiosidade e cultura contemporânea: desafios para a Psicologia. Brasília: Universa. 2012. p. 157-190.

ARRIEIRA, I. C.O. et al. O sentido da espiritualidade na transitoriedade da vida. Escola Anna Nery, v. 21, n. 1, e20170012, 2017.

BARRERA, T. L. et al. Integrating religion and spirituality into treatment for late-life anxiety: three case studies. Cognitive and Behavioral Practice, v. 19, n. 2, p. 346-358, 2012.

BIZERRIL, J.; NEUBERN, M. Experiência religiosa e subjetividade no contexto contemporâneo: diálogos entre psicologia e antropologia. In FREITAS, M. H.; PAIVA G. J. (Orgs.), Religiosidade e cultura contemporânea: desafios para a Psicologia. Brasília: Universa. 2012. p. 231-260.

BOVERO, A. et al. Spirituality, quality of life, psychological adjustment in terminal cancer patients in hospice. European Journal of Cancer Care, v. 25, n. 6, p. 961-969, 2016.

BJARNASON, D. Concept analysis of religiosity. Home Health Care Management \& Practice, v. 19, n. 5, p. 350-355. 
BRAAM, A. W.; KOENIG, H. G. Religion, spirituality and depression in prospective studies: a systematic review. Journal of Affective Disorders, v. 257, p. 428-438, 2019.

CARRETE, J. R. O retorno a James: psicologia e a amnésia da neurociência. In: FREITAS, M. H.; PAIVA G. J. (Orgs.), Religiosidade e cultura contemporânea: desafios para a Psicologia. Brasília: Universa. 2012. p. 21-54.

CONSELHO REGIONAL DE PSICOLOGIA DE SÃO PAULO (CRP-SP). Recomendações para atuação profissional da(o) psicóloga(o). Relatório síntese das discussões dos seminários estaduais psicologia, laicidade e as relações com a religião e a espiritualidade. São Paulo: CRPSP. 2015.2 Disponível em: http://www.crpsp.org.br/diverpsi/arquivos/Recomendacoes_Diverpsi.pdf

CORRÊA, C. V.; BATISTA, J. S.; HOLANDA, A. F. Coping religioso/espiritual em processos de saúde e doença: revisão da produção em periódicos brasileiros (2000-2013). PsicoFAE, Curitiba, v. 5, n. 1, p. 61-78, 2016.

COSTA, D. T. et al. Religious/spiritual coping and level of hope in patients with cancer in chemotherapy. Revista Brasileira de Enfermagem, v. 72, n. 3, p. 640-645, 2019.

CUNHA, V. F.; ROSSATO, L.; GAIA, R. S. P.; SCORSOLINI-COMIN, F. Religiosidade/Espiritualidade em saúde: uma disciplina de pós-graduação. Estudos Interdisciplinares em Psicologia, Londrina, v. 11, n. 3, p. 232-251, 2020.

CUNHA V. F.; PILLON, S. C.; ZAFAR, S.; WAGSTAFF, C.; SCORSOLINI-COMIN, F. Brazilian nurses' concept of religion, religiosity, and spirituality: a qualitative descriptive study. Nursing and Health Sciences, v. 22, p. 1161-1168, 2020.

CUNHA, V. F.; SCORSOLINI-COMIN, F. A religiosidade/espiritualidade (R/E) como componente curricular na graduação em Psicologia: relato de experiência. Psicologia Revista, São Paulo, v. 28, p. 193-214, 2019.

CUNHA, V. F.; SCORSOLINI-COMIN, F. A transcendência no cuidar: percepções de enfermeiros. Psicologia, Saúde \& Doenças, Lisboa, v. 22, n. 1, p. 270-283, 2021.

DAMIANO, R. F. et al. Brazilian scientific articles on "Spirituality, Religion and Health”. Archives of Clinical Psychiatry, São Paulo, v. 43, n. 1, p. 11-16, 2016.

DHAR, N. et al. Spiritual health, the fourth dimension: a public health perspective. WHO SouthEast Asia Journal of Public Health, v. 2, n. 1, p. 3, 2013.

ECKERSLEY, R. M. Culture, spirituality, religion and health: looking at the big picture. Medical Journal of Australia, v. 186, p. S54-S56, 2007. 
GAIA, R. S. P.; SCORSOLINI-COMIN, F. Candomblé Ketu e o sincretismo religioso no Brasil: perspectivas sobre as representações de Oxalá na diáspora. Memorandum, Belo Horizonte, v. 37, p. 1-21, 2020.

GALLARDO-PERALTA, L. P. The relationship between religiosity/spirituality, social support, and quality of life among elderly Chilean people. International Social Work, v. 60, n. 6, p. 14981511, 2017.

JAMES, W. As variedades da experiência religiosa: um estudo sobre a natureza humana. São Paulo: Cultrix, 2017.

HILL, P. C.; PARGAMENT, K. I. Advances in the conceptualization and measurement of religion and spirituality. Implications for physical and mental health research. The American Psychologist, v. 58, n. 1, p. 64-74, 2003.

HILL, P. C. et al. Conceptualizing religion and spirituality: points of commonality, points of departure. Journal for the Theory of Social Behavior, v. 30, n. 1, p. 51-77, 2000.

HOLANDA, A. F.; PEREIRA, K. C. L. Religião e espiritualidade no campo da saúde: questões para a educação superior. Paralellus, v. 11, n. 28, p. 619-640, 2020.

INSTITUTO BRASILEIRO DE GEOGRAFIA E ESTATÍSTICA. Censo Demográfico - 2010. Rio de Janeiro: IBGE, 2010.

JIMENEZ-FONSECA, P. et al. The mediating role of spirituality (meaning, peace, faith) between psychological distress and mental adjustment in cancer patients. Supportive Care in Cancer, v. 26, n. 5, p. 1411-1418, 2018.

KING, M. B.; KOENIG, H. G. Conceptualising spirituality for medical research and health service provision. BMC Health Services Research, v. 9, n. 1, p. 1-7, 2009.

KOENIG, H. G. Religion, spirituality, and health: the research and clinical implications. ISRN Psychiatry, v. 2012, p. 1-33, 2012.

KOENIG, H. G. et al. Handbook of Religion and Health. New York: Oxford University Press, 2012.

KOENIG, H. G.; AL-ZABEN, F.; VANDERWEELE, T. J. Religion and psychiatry: recent developments in research. BJPsych Advances, v. 26, n. 5, p. 262-272, 2020.

LAZENBY, J. M. On “Spirituality,” “religion,” and “religions”: a concept analysis. Palliative and Supportive Care, v. 8, p. 469-476, 2010.

LUCCHETTI, G. et al. Spirituality or religiosity: is there any difference?. Revista Brasileira de Psiquiatria, v. 37, n. 1, p. 83, 2015. 
LUCCHETTI, G.; LUCCHETTI, A. L. G. Spirituality, religion, and health: over the last 15 years of field research (1999-2013). International Journal of Psychiatry in Medicine, v. 48, n. 3, p. 199-215, 2014.

MACDONALD, D. A. et al. Spirituality as a scientific construct: testing its universality across cultures and languages. PloS One, v. 10, n. 3, p. e0117701, 2015.

MACHADO, N. J. Psicologia, espiritualidade e epistemologias não hegemônicas. In CONSELHO REGIONAL DE PSICOLOGIA DE SÃO PAULO. Psicologia, espiritualidade e epistemologias não-hegemônicas - Volume 3 (Coleção Psicologia, laicidade e as relações com a religião e a espiritualidade). São Paulo: CRP-SP, 2016. p. 17-30.

MARALDI, E. O. Psicoterapia, identidade e misticismo new age: configurações contemporâneas. In CONSELHO REGIONAL DE PSICOLOGIA DE SÃO PAULO (CRP-SP). Laicidade, religião, direitos humanos e políticas públicas - Volume 1 (Coleção Psicologia, laicidade e as relações com a religião e a espiritualidade). São Paulo: CRP-SP, 2016. p. 125-128.

MISHRA, S. K. et al. Spirituality and religiosity and its role in health and diseases. Journal of Religion and Health, v. 56, p. 1282-1301, 2017.

MOREIRA-ALMEIDA, A.; LOTUFO NETO, F.; KOENIG, H. G. Religiousness and mental health: a review. Revista Brasileira de Psiquiatria, v. 28, n. 3, p. 242-250, 2006.

NEWPORT, F. Five Key Findings on Religion in the US. Gallup, 2016. Disponível em http://www.gallup.com/poll/200186/five-key-findings-religion.aspx. Acesso em: 25 de fev. de 2021.

NASH, S.; NASH, P.; DARBY, K. Spiritual care with sick children and young people: a handbook for chaplains, paediatric health professionals, arts therapists and youth workers. Jessica Kingsley Publishers, 2015.

OMAN, D. Defining religion and spirituality. In PALOUTZIAN, R. F.; PARK, C. L. (Eds.), Handbook of the psychology of religion and spirituality. New York: The Guilford Press, 2013. p. 23-47.

PALOUTZIAN, R. F. Psychology of religion in global perspective: logic, approach, concepts. The International Journal for the Psychology of Religion, v. 27, n. 1, p. 1-13, 2017.

PANZINI, R. G.; BANDEIRA, D. R. Coping (enfrentamento) religioso/espiritual. Revista de Psiquiatria Clínica, v. 34, n. 1, p. 126-135, 2007.

PARGAMENT, K. I. The psychology of religion and coping: theory, research, practice. New York: Guilford Press, 1997. 
PARGAMENT, K. I. Spiritually integrated psychotherapy: understanding and addressing the sacred. New York: The Guilford Press, 2007.

PERES, M. F. P. et al. Mechanisms behind religiosity and spirituality's effect on mental health, quality of life and well-being. Journal of Religion and Health, v. 57, n. 5, p. 1842-1855, 2018.

PINTO, A. N.; FALCAO, E. B. M. Religiosidade no contexto médico: entre a receptividade e o silêncio. Revista Brasileira de Educação Médica, v. 38, n. 1, p. 38-46, 2014.

PRÉCOMA, D. B. et al. Atualização da Diretriz de Prevenção Cardiovascular da Sociedade Brasileira de Cardiologia - 2019. Arquivos Brasileiros de Cardiologia, v. 113, n. 4, p. 787-891, 2019.

PUCHALSKI, C. M. et al. Improving the spiritual dimension of whole person care: reaching national and international consensus. Journal of Palliative Medicine, v. 17, n. 6, p. 642-656, 2014.

ŘÍČAN P. Spirituality: the story of a concept in the psychology of religion. Archiv fur Religionspsychologie, v. 26, p. 135-156, 2004.

ROSSATO, L.; ULLÁN, A. M.; SCORSOLINI-COMIN, F. Religious and spiritual practices used by children and adolescents to cope with cancer. Journal of Religion \& Health, v. 60, n. 2, p. 117, 2021.

SATARIANO, B. Religion, health, social capital and place: the role of the religious, social processes and the beneficial and detrimental effects on the health and wellbeing of inhabitants in deprived neighborhoods in Malta. Journal of Religion and Health, p. 1-14, 2020.

SHATTUCK, E. C.; MUEHLENBEIN, M. P. Religiosity/spirituality and physiological markers of health. Journal of Religion and Health, v. 59, n. 2, p. 1035-1054, 2020.

SCHWALM, F. D. et al. Is there a relationship between spirituality/religiosity and resilience? A systematic review and meta-analysis of observational studies. Journal of Health Psychology, p. 1359105320984537, 2021.

SMOTHERS, Z. P. W; KOENIG, H. G. Spiritual interventions in veterans with PTSD: a systematic review. Journal of Religion and Health, v. 57, n. 5, p. 2033-2048, 2018.

SOUTHARD, M. E. Spirituality: the missing link for holistic health care. Journal of Holistic Nursing, v. 38, n. 1, p. 4-7, 2020.

STEINHAUSER, K. E. et al. State of the science of spirituality and palliative care research part I: definitions, measurement, and outcomes. Journal of Pain and Symptom Management, v. 54, n. 3, p. 428-440, 2017.

SWINTON, M. et al. Experiences and expressions of spirituality at the end of life in the intensive care unit. American Journal of Respiratory and Critical Care Medicine, v. 195, n. 2, p. 198204, 2017. 
SZCZEŚNIAK, M.; KROPLEWSKI, Z.; SZAŁACHOWSKI, R. The mediating effect of coping strategies on religious/spiritual struggles and life satisfaction. Religions, v. 11, n. 4, p. 195, 2020.

VASCONCELOS, E. M. (Org.). A espiritualidade no trabalho em saúde. São Paulo: Hucitec, 2015.

WALTERS, K.; BENJAMINS, M. R. Religious beliefs about health and the body and their association with subjective health. Journal of Religion and Health, p. 1-16, 2021.

WEATHERS, E. Spirituality and health: A Middle Eastern perspective. Religions, v. 9, n. 2, p. 33, 2018.

WORLD HEALTH ORGANIZATION. Division of mental health and prevention of substance abuse. WHOQOL and spirituality, religiousness and personal beliefs (SRPB). Genève: World Health Organization, 1998.

ZIMMER, Z. et al. Spirituality, religiosity, aging and health in global perspective: a review. SSMPopulation Health, v. 2, p. 373-381, 2016.

ZINNBAUER, B. J.; PARGAMENT, K. I. Religiousness and Spirituality. In PALOUTZIAN, R. F.; PARK, C. L. (Eds.), Handbook of the psychology of religion and spirituality. New York: The Guilford Press, 2005. p. 21-42. 